\title{
Biodegradable poly-L-lactide-co-glycolide copolymer pin fixation of a traumatic patellar osteochondral fragment in an 11-year-old child: A novel surgical approach
}

\author{
JUHA-JAAKKO SINIKUMPU and WILLY SERLO \\ Department of Pediatric Surgery and Orthopedics, Oulu University Hospital, Oulu, 90029 OYS, Finland
}

Received May 18, 2015; Accepted July 21, 2016

DOI: $10.3892 /$ etm.2016.3934

\begin{abstract}
Treating displaced patellar bone fractures in growing children remains a challenge for orthopedic surgeons. Removal of loose bone fragments may prolong healing time and result in early onset osteoarthrosis. Therefore, primary fixation of osteochondral fragments is preferred. Metallic pin and screw implants are typically used for fixation, as there is little evidence available regarding the use of modern biodegradable implants in traumatic patellar fractures of a premature skeleton. The present report describes a novel operative technique using headless poly-L-lactide-co-glycolide (PLGA) pins in treating an 11-year-old girl with a patellar fracture from a cycling injury. The surgical technique of this procedure is described in detail in the current report. Excellent subjective outcomes were achieved from this surgery, with superb bone healing according to follow-up radiographic and computerized tomography scans. In conclusion, the results of this case indicate that, similarly to osteochondritis, intra-articular osteochondral fractures in children may be fixed using biodegradable PLGA pins. Randomized clinical trials should be performed to confirm this finding and evaluate the use of PLGA pins as a treatment for adolescent osteochondral fractures.
\end{abstract}

\section{Introduction}

Osteochondral fractures of the patella may result in premature osteoarthritis, chronic swelling, pain and subsequent decreased physical activity. The fractures are usually associated with acute patellar dislocation while such a fracture is observed in $39-54 \%$ of the acute dislocations $(1,2)$. The estimated incidence of patellar dislocation in children is $43 / 100,000$ yearly (1). Knee injuries in children and adolescents are becoming more

Correspondence to: Dr Juha-Jaakko Sinikumpu, Department of Pediatric Surgery and Orthopedics, Oulu University Hospital, PO Box 23, Oulu, 90029 OYS, Finland

E-mail: juha-jaakko.sinikumpu@ppshp.fi

Key words: patellar fracture, osteochondral fragment, fixation, biodegradable, poly-L-lactide-co-glycolide, children, adolescents common and the main reasons for this are participation in organized sports, increased female participation in high risk sports, potentially decreased motor skills in this population and the improved diagnostic skills of the treating physicians $(3,4)$. The average age of patients with osteochondral fracture of the patella following patellar dislocation is 14.6 years (5). Patellar injury is particularly detrimental to children, who have long life expectancies, resulting in morbidity being long-lasting. Numerous treatment methods exist while non-operative care can be appropriate in stable, asymptomatic cases (5). Fixation, excision of the loose bony body, and marrow stimulating procedures such as donor site microfracturing are other treatment options $(6,7)$. Fixation is the preferred treatment for unstable osteochondral fractures, however, there are disadvantages to traditional metallic implants and the less modern biodegradable implants: The metallic implants require removal and the less modern biodegradable pins exhibit an inflammatory reaction elicited from degradation products (8-10). Biodegradable implants are not common in injury-based patellar fractures in children, although they are a widely accepted method of treatment in osteochondritis dissecans, while both smooth pins and screws are commonly used $(11,12)$.

The current report describes a novel operative technique using headless poly-L-lactide-co-glycolide (PLGA) pins in the treatment of a young child with such an injury-based fracture. Written informed consent was obtained prior to this study.

\section{Case report}

The patient was an 11-year-old girl who did not have any chronic disease. The patient fell whilst cycling and injured her right knee. She was admitted to Oulu University Hospital (Oulu, Finland) in November 2014. In the primary radiographs a loose bone fragment was observed in the knee joint (Fig. 1). A computerized tomography (CT) scan was then performed, which identified that the fragment originated from a stress-bearing area of the distal apex of the patellae. The fragment was $\sim 10 \times 10 \mathrm{~mm}$ in size and comprised the joint cartilage surface and a thin layer of underlying bone tissue (Fig. 2). No other acute musculoskeletal damage was observed in the CT scan.

Clinical investigation was repeated under general anesthesia during surgery 5 days later and no patellar instability was found. Lateral entry arthroscopy identified a large patellar osteochondral fragment. Arthrotomy, instead of 

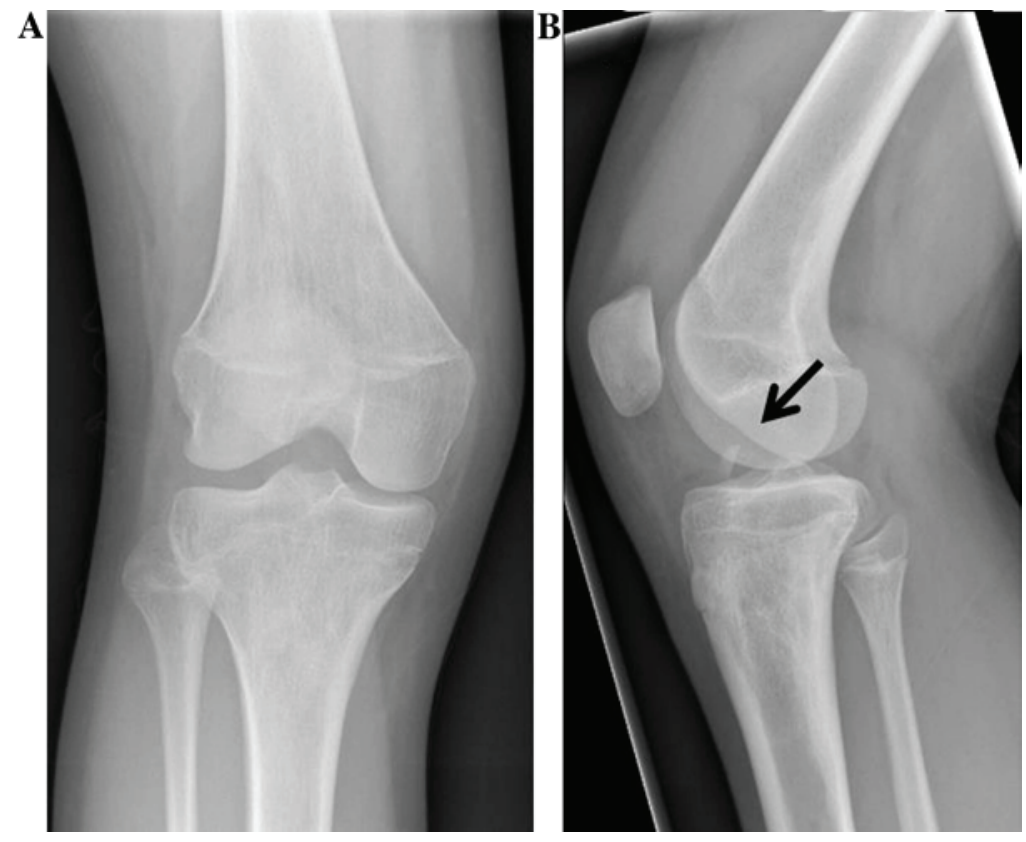

Figure 1. Primary radiographs showed a loose bone fragment (arrow) in the right knee joint. (A) Antero-posterior and (B) lateral projections.
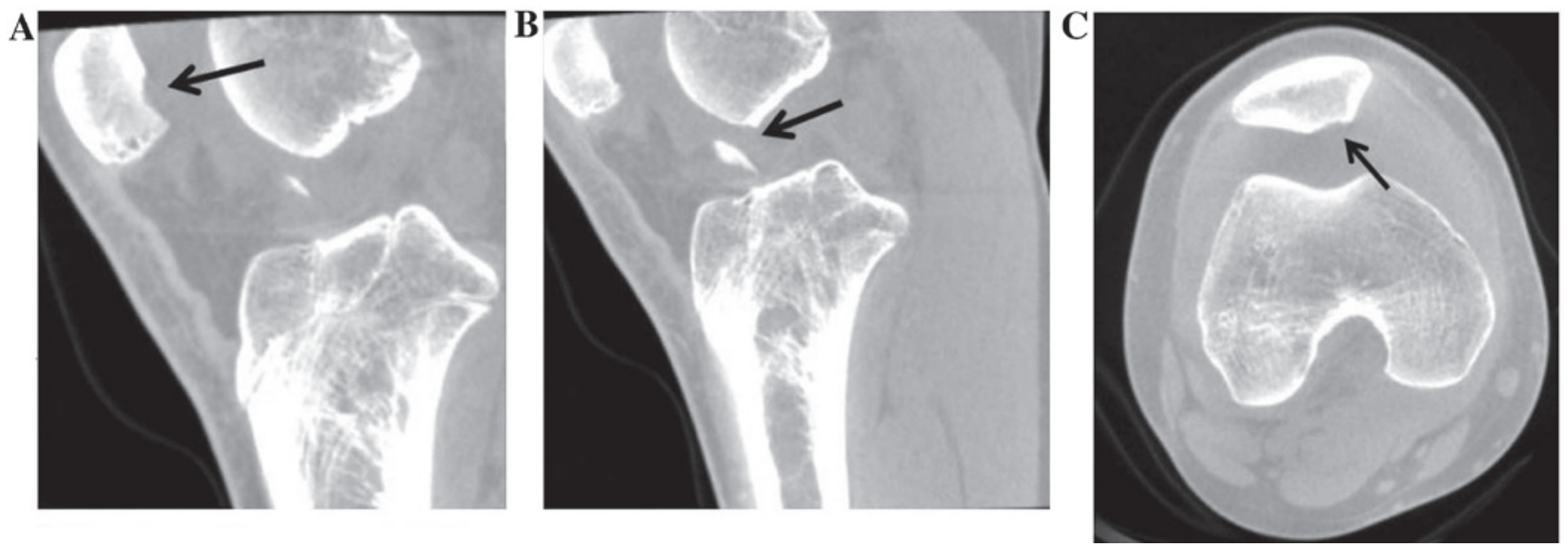

Figure 2. (A) Computerized tomography (CT) scan, sagittal view, showed the origin of the loose body in the patella (arrow). (B) The loose bone body (arrow) was found to be severely displaced in the sagittal CT view. (C) Transverse view of the primary CT scan demonstrates the origin (arrow) of the donor in the stress-bearing area at the distal apex of the right patella.

arthroscopy-guided fixation, was necessary due to the small dimensions of the child patient. The knee was drained and a vertical parapatellar technique was used to dissect soft tissues in the approach to the patella, which was laterally everted $90^{\circ}$ using forceps, in order to gain direct access to the lesion. The surface of the damaged area was rasped and the fragment was adjusted into its original location. The fragment was pressed against the patellar bone, followed by fixation with two $1.4-\mathrm{mm}$ and one $2.0-\mathrm{mm}$ Kirschner wires. Thereafter, the wires were replaced with two $1.5-\mathrm{mm}$ and one $2.0-\mathrm{mm}$ PLGA (ActivaPin; Bioretec, Ltd., Tampere, Finland) pins. An implant-specific ActivaPin-applicator (Bioretec, Ltd.) was used, so that no notches or unevenness were left at the joint surface.

Postoperatively, an individual shell plaster using flexible synthetic material was applied to the knee joint. No weight bearing was allowed for 2 weeks following surgery, in order to protect the patella from compression against the femoral trochlear sulcus. Three weeks following the surgery, the patient visited a surgeon at an outpatient clinic. Partial weight bearing was allowed ( $25 \mathrm{~kg})$, a hinge joint orthosis was ordered to support the knee and instructions on physical exercises were provided by a physiotherapist familiar with pediatric trauma. Exercises were introduced to be performed at home 2 or 3 times a day in order to maintain muscle strength. Six weeks following the surgery, the patellar bone appeared intact in radiographs (Fig. 3) and free movement was allowed. A CT scan was performed eight weeks following the surgery, which verified good bone healing (Fig. 4). The femoral-patellar joint looked intact. The long-term result was evaluated 13 months following the surgery. The patella was stable and the knee had a full range of motion. The child had no long-lasting symp- 

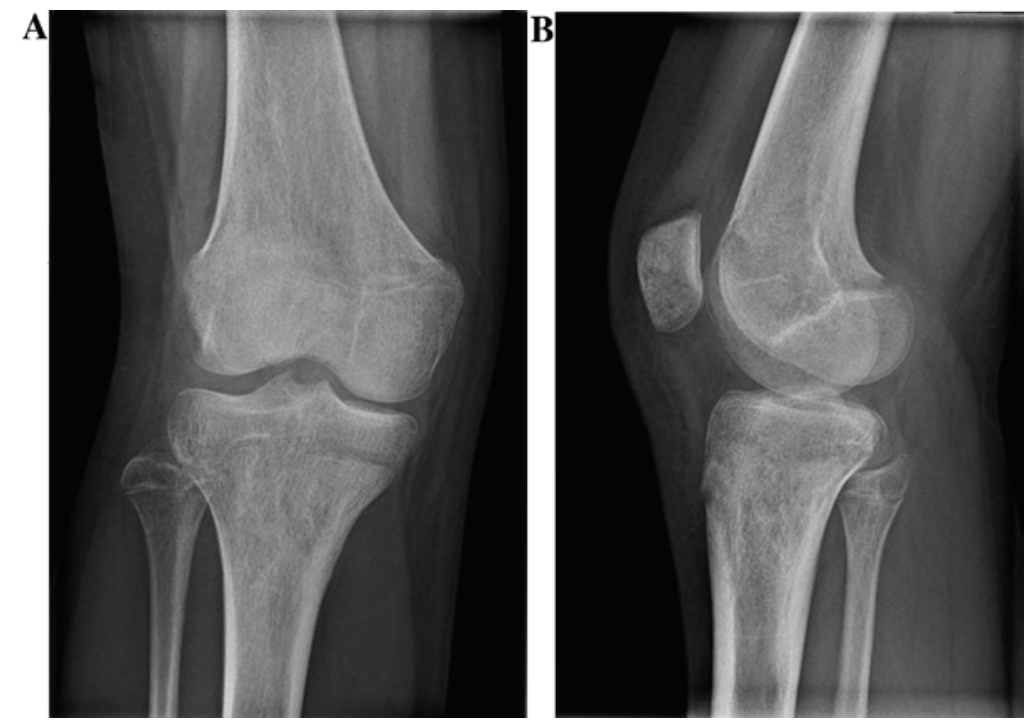

Figure 3. Radiographs 6 weeks following surgery. The loose bone fragment was ossifying and the patellar joint surface appeared smooth in (A) antero-posterior and (B) lateral views.
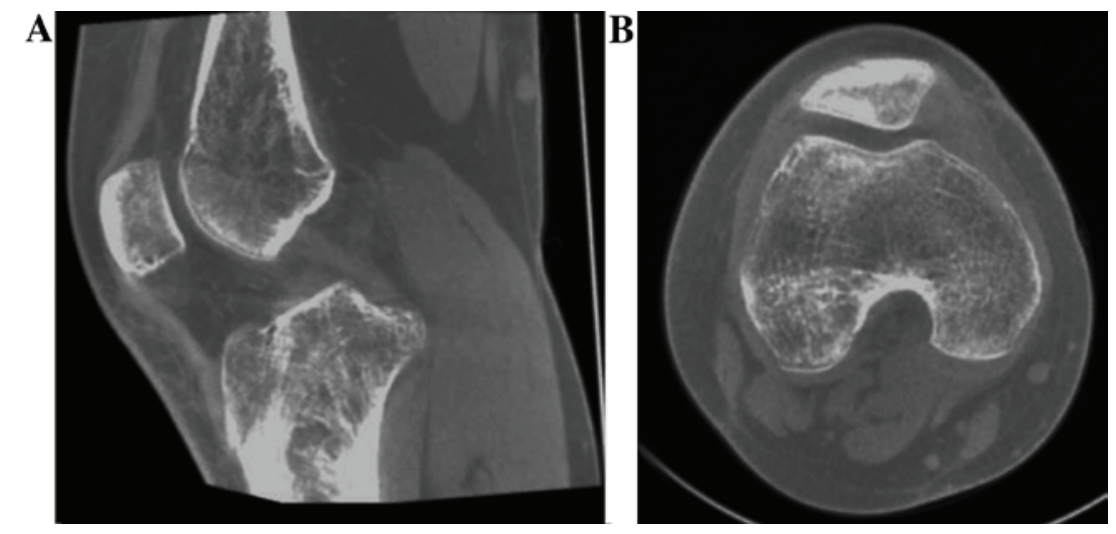

Figure 4. Computerized tomography scans to evaluate fracture healing 8 weeks following surgery. Good bone healing was observed and the femoral-patellar joint appeared intact. (A) Sagittal view and (B) transverse view.
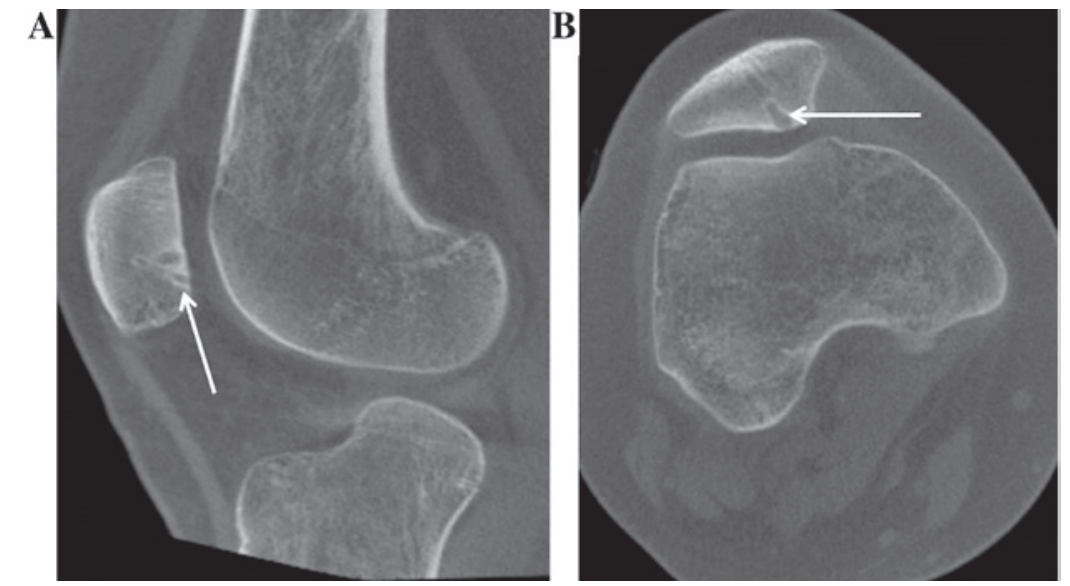

Figure 5. Computerized tomography scans showing (A) sagittal and (B) transverse views 13 months following surgery. A smooth and intact knee joint surface was observed and the implants (arrows) were degrading, visualized by edema at their outlines due to resolution, and replacement by human tissue.

toms and had returned to pre-injury activity levels. A smooth joint surface and firm union was observed in cone beam CT imaging. This imaging also showed edema in the outlines of the implants, indicating that the degradation process of the orthopedic implants was on-going, after which they were to be replaced by bone tissue (Fig. 5). 


\section{Discussion}

The present report describes an 11-year-old girl, who was successfully operated on for traumatic patellar osteochondral fracture by fixing the loose fragment with PLGA pins. Bioabsorbable pins are typically used to treat osteochonditis dissecans particles in juvenile skeletons (12). However, to best of our knowledge, this method has not been widely reported previously in regards to injury-based patellar fractures in children. In addition, the material of the implants used in the current report is different from the traditional absorbable materials previously reported to be used in orthopedics; traditional absorbable materials have been shown to affect the outcome, for example, there have been problems with osteolysis when using polyglycolic acid pins in immature and mature tissues (13-16).

The technique used in the current report was straightforward, with excellent short- and long-term results. This indicates that PLGA pins may be used to fix an intra-articular fracture in an immature skeleton. In addition, this treatment was advantageous as no further surgery was needed to remove the biodegradable implants. The implants will degrade over time, resulting in the patella being comprised and shaped like it was prior to the injury.

The prevalence of osteochondral fractures in children is unknown (17). However, it has been suggested that knee injuries in children and adolescents are increasing (3). In cases of knee hemarthrosis, the incidence of patellar osteochondral fractures is $5 \%$ (18). In addition, the injury may be more common than previously suspected, as patellar fractures may not be recognized in normal radiographs, with magnetic resonance imaging needed to evaluate the osteochondral damage (19).

In intra-articular osteochondral fractures of the patella it is important to salvage the cartilage joint surface, particularly in growing children, to prevent later symptoms and early-onset osteoarthrosis (20). Cartilage damage is a primary factor in long-term prognosis following patellar injury (21). Extirpation of loose fragments of joint surface results in fibrocartilage tissue formation (22), thus removal is only acceptable for small fragments not involved in the central part of the joint or stress-bearing areas. Consequently, surgical repositioning and fixation of fragments is the preferred method of treatment. Numerous techniques have been described, with screw and pin fixations being the most common (23-28). However, traditional metallic implants can cause mechanical damage of the joint if the surrounding bone collapses or cartilage wears out and removal of the implants may be necessary (29). The primary advantage of absorbable implants is that a second surgery for removal is not necessary (17).

A previous study has determined that biodegradable pin fixation is a feasible technique for the treatment of knee injuries in adolescents (7). In addition, other types of biodegradable implants, including screws and nails, have been reported (30). Despite the better compression provided by screws, the prominence of the screw head may result in a more uneven joint surface compared with pins $(17,31)$. In the current report, satisfactory compression was achieved with PLGA pins, where a tight 'drill' hole was made using conventional Kirschner wire as a bore bit, instead of a proper drilling. The stability of fixation was manually tested during the surgery. Furthermore, the material of the implant used in the current report swells between 1 and $2 \%$ when it comes into contact with human tissue, further increasing the rigidity of the fixation (32).

The technique described in the current report resulted in an excellent recovery following PLGA pin fixation of an adolescent traumatic patellar osteochondral fracture. Radiographic imaging identified complete ossification of the loose fragment and CT imaging demonstrated an intact knee joint surface. Bone healing following treatment was fast, with osteosynthesis becoming stable VI weeks postoperatively. Thirteen months postoperatively, the outlines of the implants were partially recognized in CT imaging, as a result of implant resolution, demonstrating on-going replacement with human tissue. In conclusion, the novel surgical approach to treating children with a traumatic patellar osteochondral fracture by PLGA pins described in the current report warrants future randomized clinical trials, in order to validate the superiority of this technique over the traditional metallic implants used in the pediatric population.

\section{Acknowledgements}

Dr Juha-Jaakko Sinikumpu received a grant supporting the current report from Bioretec, Ltd. (Tampere, Finland).

\section{References}

1. Nietosvaara Y, Aalto K and Kallio PE: Acute patellar dislocation in children: Incidence and associated osteochondral fractures. J Pediatr Orthop 14: 513-515, 1994.

2. Nomura E, Inoue M and Kurimura M: Chondral and osteochondral injuries associated with acute patellar dislocation. Arthroscopy 19: 717-721, 2003.

3. Seil R, Weitz FK and Pape D: Surgical-experimental principles of anterior cruciate ligament (ACL) reconstruction with open growth plates. J Exp Orthop 2: 11, 2015.

4. Aichroth PM, Patel DV and Zorrilla P: The natural history and treatment of rupture of the anterior cruciate ligament in children and adolescents. A prospective review. J Bone Joint Surg Br 84: 38-41, 2002.

5. Lee BJ, Christino MA, Daniels AH, Hulstyn MJ and Eberson CP: Adolescent patellar osteochondral fracture following patellar dislocation. Knee Surg Sports Traumatol Arthrosc 21: 1856-1861, 2013.

6. Gudas R, Kalesinskas RJ, Kimtys V, Stankevicius E, Toliusis V, Bernotavicius $\mathrm{G}$ and Smailys A: A prospective randomized clinical study of mosaic osteochondral autologous transplantation versus microfracture for the treatment of osteochondral defects in the knee joint in young athletes. Arthroscopy 21: 1066-1075, 2005.

7. Matsusue Y, Nakamura T, Suzuki S and Iwasaki R: Biodegradable pin fixation of osteochondral fragments of the knee. Clin Orthop Relat Res 166-173, 1996.

8. Din R, Annear P and Scaddan J: Internal fixation of undisplaced lesions of osteochondritis dissecans in the knee. J Bone Joint Surg Br 88: 900-904, 2006.

9. Nakagawa T, Kurosawa H, Ikeda H, Nozawa M and Kawakami A: Internal fixation for osteochondritis dissecans of the knee. Knee Surg Sports Traumatol Arthrosc 13: 317-322, 2005.

10. Mainil-Varlet P, Rahn B and Gogolewski S: Long-term in vivo degradation and bone reaction to various polylactides. 1. One-year results. Biomaterials 18: 257-266, 1997.

11. Rehm KE, Helling HJ and Gatzka C: New developments in the application of resorbable implants. Orthopade 26: 489-497, 1997 (In German).

12. Adachi N, Deie M, Nakamae A, Okuhara A, Kamei G and Ochi M: Functional and radiographic outcomes of unstable juvenile osteochondritis dissecans of the knee treated with lesion fixation using bioabsorbable pins. J Pediatr Orthop 35: 82-88, 2015. 
13. Fraser RK and Cole WG: Osteolysis after biodegradable pin fixation of fractures in children. J Bone Joint Surg Br 74: 929-930, 1992.

14. Böstman O and Pihlajamäki $\mathrm{H}$ : Clinical biocompatibility of biodegradable orthopaedic implants for internal fixation: A review. Biomaterials 21: 2615-2621, 2000.

15. Rokkanen P, Böstman O, Hirvensalo E, Partio EK, Mäkelä EA, Pätiälä $\mathrm{H}$ and Vihtonen $\mathrm{K}$ : Bioabsorbable implants in orthopaedics. Curr Orthop 13: 223-228, 1999

16. Rokkanen PU, Böstman O, Hirvensalo E, Mäkelä EA, Partio EK, Pätiälä H, Vainionpää SI, Vihtonen K and Törmälä P: Bioabsorbable fixation in orthopaedic surgery and traumatology. Biomaterials 21: 2607-2613, 2000.

17. Chotel F, Knorr G, Simian E, Dubrana F and Versier G; French Arthroscopy Society: Knee osteochondral fractures in skeletally immature patients: French multicenter study. Orthop Traumatol Surg Res 97 (8 Suppl): S154-S159, 2011.

18. Vähäsarja V, Kinnuen P and Serlo W: Arthroscopy of the acute traumatic knee in children. Prospective study of 138 cases. Acta Orthop Scand 64: 580-582, 1993.

19. Vellet AD, Marks PH, Fowler PJ and Munro TG: Occult posttraumatic osteochondral lesions of the knee: Prevalence, classification, and short-term sequelae evaluated with MR imaging. Radiology 178: 271-276, 1991.

20. Kramer DE and Pace JL: Acute traumatic and sports-related osteochondral injury of the pediatric knee. Orthop Clin North Am 43: 227-236.vi, 2012.

21. Schmal H, Strohm PC, Niemeyer P, Reising K, Kuminack K and Sudkamp NP: Fractures of the patella in children and adolescents Acta Orthop Belg 76: 644-650, 2010.

22. Scopp JM and Mandelbaum BR: Cartilage restoration: Overview of treatment options. J Knee Surg 17: 229-233, 2004.

23. Sgaglione NA, Miniaci A, Gillogly SD and Carter TR: Update on advanced surgical techniques in the treatment of traumatic focal articular cartilage lesions in the knee. Arthroscopy 18 (2 Suppl 1): S9-S32, 2002.
24. Beasley LS and Vidal AF: Traumatic patellar dislocation in children and adolescents: Treatment update and literature review. Curr Opin Pediatr 16: 29-36, 2004.

25. Jakob RP, Franz T, Gautier E and Mainil-Varlet P: Autologous osteochondral grafting in the knee: Indication, results, and reflections. Clin Orthop Relat Res 170-184, 2002.

26. Cain EL and Clancy WG: Treatment algorithm for osteochondral injuries of the knee. Clin Sports Med 20: 321-342, 2001.

27. Mandelbaum BR, Browne JE, Fu F, Micheli L, Mosely JB Jr, Erggelet C, Minas T and Peterson L: Articular cartilage lesions of the knee. Am J Sports Med 26: 853-861, 1998.

28. Kish G, Módis L and Hangody L: Osteochondral mosaicplasty for the treatment of focal chondral and osteochondral lesions of the knee and talus in the athlete. Rationale, indications, techniques, and results. Clin Sports Med 18: 45-66.vi, 1999.

29. Korhonen J, Sinikumpu JJ, Harmainen S, Ryhänen J, Kallio P and Serlo W: Removal of osteosynthesis material in children and young people. Duodecim 130: 689-695, 2014 (In Finnish).

30. Fuchs M, Vosshenrich R, Dumont C and Stürmer KM: Refixation of osteochondral fragments using absorbable implants. First results of a retrospective study. Chirurg 74: 554-561, 2003 (In German).

31. Hirsch G and Boman A: Osteochondral fractures of the knee in children and adolescents treatment with open reduction and osteosynthesis using biodegradable pins. Techniques in Orthopaedics 13: 139-142, 1998.

32. Sinikumpu JJ, Keränen J, Haltia AM, Serlo W and Merikanto J: A new mini-invasive technique in treating paediatric diaphyseal forearm fractures by bioabsorbable elastic stable intramedullary nailing: A preliminary technical report. Scand J Surg 102: 258-264, 2013. 